\title{
Outcome of wheeze in childhood: the influence of atopy
}

\author{
S. Ross*+, D.J. Godden*, M. Abdalla**, D. McMurray*+, A. Douglas*+, D. Oldman+, \\ J.A.R. Friend ${ }^{++}$, J.S. Legge ${ }^{++}$, J.G. Douglas ${ }^{++}$
}

Outcome of wheeze in childhood: the influence of atopy. S. Ross, D.J. Godden, M. Abdalla, D. McMurray, A. Douglas, D. Oldman, J.A.R. Friend, J.S. Legge, J.G. Douglas. CERS Journals Ltd 1995.

ABSTRACT: We have previously demonstrated that the adult outcome of childhood asthma differs from that of wheeze occurring only in the presence of infection. This paper examines the role of atopy in relation to outcome.

We investigated the atopic status, current symptoms and bronchial reactivity to methacholine of 235 subjects aged 34-40 yrs, originally classified at age 10-15 yrs as having asthma (asthma group), wheeze only in the presence of infection (wheezy group), or no respiratory symptoms (comparison group).

Subjects from the original asthma group were more likely to be atopic as defined by skin test reactivity, total serum immunoglobulin $\mathrm{E}$ (IgE) measurement or specific IgE radio allergosorbent test (RAST) measurement than those from the wheezy group. The wheezy group differed significantly from the reference group only in RAST results, when other variables were taken into account. In a logistic regression model, the important independent predictors for adult wheezing symptoms were original group, atopy and current smoking. Methacholine responsiveness was independently associated with original group (the asthma group were more likely to respond positively), atopy and female gender.

The results suggest that atopy is an important predictor for wheeze and bronchial hyperreactivity in middle age. However, the difference in outcome for children who had asthma compared to those who had wheeze only in the presence of infection cannot be explained by atopy alone.

Eur Respir J., 1995, 8, 2081-2087.

\begin{abstract}
*Depts of Medicine and Therapeutics, and +Sociology, University of Aberdeen, Aberdeen, Scotland. **Health Services Research Unit, University of Aberdeen, Aberdeen, Scotland. "Thoracic Medicine, Aberdeen Royal Hospitals Trust, Aberdeen, Scotland.
\end{abstract}

Correspondence: S. Ross, Dept of General Practice, University of Glasgow, Woodside Health Centre, Barr Street, Glasgow, Scotland G20 7LR

Keywords: Adult asthma, atopy, childhood asthma, methacholine challenge, outcome

Received: December 231994

Accepted after revision August 41995

The study was supported by the National Asthma Campaign and Pharmacia Diagnostics UK. The Health Service Research Unit is funded by the Chief Scientist Office of the Scottish Home and Health Department. However, the views expressed in this article are those of the authors.
Historically, wheezing illnesses in children and young adults carried two distinct clinical labels, "wheezy bronchitis" and "asthma". In the early 1980s, largely as a esult of concerns regarding undertreatment of asthma, it became the norm to regard the majority of wheezing illnesses as asthma, including those which would previously have been labelled as wheezy bronchitis [1, 2].

More recently, the validity of this approach has been questioned. In a study of outcome for children who wheezed in infancy, MARTINEz et al. [3] demonstrated two distinct subgroups: a subgroup in whom wheeze resolved by the age of $6 \mathrm{yrs}$, who had impaired small airway function but no evidence of atopy; and a second subgroup in whom wheezing persisted at age 6 yrs, who had elevated serum immunoglobulin E (IgE) levels and were more likely to have a maternal history of asthma [3]. We have also suggested the presence of subgroups with differing aetiologies for childhood wheeze, and this report describes the outcome in middle age of children first studied in later childhood.

In 1964, the Medical Research Council Medical Sociology Research Unit carried out a random community survey of the parents of one in five children at primary school in Aberdeen, Scotland. A total of 2,511 children were included, and those who were reported as having wheezy symptoms underwent clinical assessment. The diagnosis of asthma, defined as "recurrent dyspnoea of an obstructive type without other demonstrable cause" was confirmed in 121 subjects [4, 5]. These children were reported as having wheezing attacks precipitated by a range of factors, including exercise, cold weather, frost, hot weather, damp, mist, fog, pollen, cut grass, and, in 50 cases, no demonstrable factor. A further 167 were classified as having "wheeze in the presence of upper respiratory infection" only. No objective evidence of infection was presented, but they appeared to fit the category of "wheezy bronchitis", which was in widespread clinical use at the time. In 1989, we studied both groups of subjects, by that time aged 34-40 yrs, together with a random sample of 167 comparison subjects drawn from those who reported no respiratory symptoms in the 1964 survey [6, 7]. Those subjects who had asthma in childhood were more likely to have respiratory symptoms (wheeze or phlegm) which interfered with activities, to have lower forced expiratory volume in one second (FEV1) (\% predicted) values and to have greater bronchial reactivity than comparison subjects. In contrast, the prognosis for those subjects who had wheeze in the presence of 
infection as children was better: symptoms in adulthood were less frequent and less severe, and their ventilatory function and bronchial reactivity to methacholine did not differ from comparison subjects.

These findings demonstrated that the natural history of wheeze only in the presence of infection was different from that of asthma and led us to question the role of atopy in determining outcome. Atopic status of the subjects was not measured in 1964 but was examined in 1989. We have, therefore, examined the roles of original classification (asthma, wheeze with infection or comparison) and atopic status on outcome as defined by adult symptoms and bronchial reactivity.

\section{Method}

\section{Subjects}

All subjects identified in Aberdeen in 1964 [4, 5] as having childhood asthma, defined as "recurrent dyspnoea of an obstructive type without other demonstrable cause" (asthma group; $\mathrm{n}=121$ ), or "wheeze in the presence of upper respiratory infection" (wheezy group; $\mathrm{n}=167$ ) were selected for follow-up 25 yrs later in 1989, when they were aged $34-40$ yrs $[6,7]$. The basis for the original 1964 classification for these two groups was derived from questionnaire information and from clinical assessment. The clinical examination included general and respiratory system examination, but did not include any assessment of allergic status. In 1989, an additional comparison group was randomly sampled from the 2,223 who had no respiratory symptoms in the original study (comparison group; $n=167$ ): questionnaire information alone was available for asymptomatic children.

Subjects still living in the Grampian region of Scotland in 1989 were interviewed over a period of 14 months: subjects were selected in random order from each of the three groups, to reduce bias. The interview included questions about past and current respiratory symptoms, other allergic conditions and smoking habit. All subjects were invited to attend the pulmonary function laboratory for methacholine challenge testing, skin prick testing and blood sampling for total and specific IgE (radio allergosorbent test (RAST)) measurements.

\section{Methacholine challenge testing}

Methacholine challenge tests were carried out using the method of YAN et al. [8]. Subjects were asked to omit bronchodilator inhalers for a minimum of $8 \mathrm{~h}$ before attending for challenge testing. FEV1 was measured using a wedge spirometer (Vitalograph, UK). Subjects were excluded from the test if baseline FEV1 was less than $70 \%$ predicted, or if they had suffered from a respiratory tract infection in the previous 2 weeks. One pregnant subject was also excluded. Results of the methacholine challenge tests are expressed as "negative" for subjects whose FEV 1 did not fall by $20 \%$ from baseline over the course of the test (starting with a dose of $0.016 \mu \mathrm{mols}$ of methacholine followed by doubling cumulative doses, up to a maximum cumulative dose of $16.38 \mu \mathrm{mols}$ of methacholine), and "positive" for those subjects whose FEV1 fell by $20 \%$, at which point the challenge was stopped and inhaled salbutamol was given to reverse bronchoconstriction.

\section{Skin tests}

Allergen skin tests were performed using Phazets allergen-coated sterile lancets (Pharmacia Diagnostics, Milton Keynes, UK). The allergens chosen for the study were cat dander, grass pollens and house dust mite. Histamine and an uncoated Phazet were used as the positive and negative controls, respectively. The Phazet was applied to the forearm at a $90^{\circ}$ angle, and held in place for at least one second. Wheal sizes were measured $10 \mathrm{~min}$ following the tests by means of the cellophane tape technique [9], and the mean diameters calculated from the long axis and its perpendicular. Wheals with an average diameter of at least $3 \mathrm{~mm}$ were counted as positive responses [10]. Subjects who responded positively to the negative control $(n=6)$ or negatively to the positive control $(n=1)$ were excluded.

\section{Total and specific IgE (RAST)}

Venous blood samples of $10 \mathrm{~mL}$ were taken for total $\mathrm{IgE}$ and RAST testing. Total IgE is expressed as IU. $\mathrm{mL}^{-1}$. Specific IgE tests for cat dander, mixed grass pollen, house dust mite, dog dander, mixed moulds, tree pollen and weeds were performed by a standard RAST technique using a paper disk containing the relevant allergens (Phadiatop, Pharmacia Diagnostics, Milton Keynes, UK). RAST results for individual allergens are reported as positive when the RAST class was one or greater $\left(>0.35 \mathrm{IU} \cdot \mathrm{mL}^{-1}\right)$, and negative when the RAST response was zero $\left(<0.35 \mathrm{IU} \cdot \mathrm{mL}^{-1}\right)$. The overall RAST result is reported as positive for subjects with at least one positive allergen result and negative for those with all negative results.

\section{Data analysis}

Data were analysed using SPSSX on the University of Aberdeen central computer system. Normally distributed variables are presented as means and 95\% confidence intervals (CI) of the means. Variables which were log transformed to achieve normality are presented as geometric means and 95\% CI. Comparisons between the groups for such variables were conducted by analysis of variance tests ( $\mathrm{F}$ test), and the results reported as the difference in the means (and 95\% CI) for normally distributed variables, or the ratio of the means (and 95\% CI) for log transformed variables. Binary variables are presented as number and percentage: comparisons between groups for these variables were assessed by Chi-squared $\left(\chi^{2}\right)$ test. To test whether the difference in binary variables between 
the original groups followed a decreasing trend (e.g. atopic symptoms experienced most in the asthma group, less in the wheezy group and least in the comparison group), Chi-squared tests for trend were conducted. Logistic regression analysis was used to predict the result of the methacholine challenge test and adult wheezing on the basis of original group, gender, smoking history and the results of allergy testing.

\section{Results}

Of the 287 subjects interviewed, 78 were from the group who were originally defined as having asthma, 111 from the group who had "wheeze in the presence of upper respiratory infection", and 98 who had no respiratory symptoms in 1964 (table 1). Gender distribution of those interviewed reflected the composition of the original groups $[4,5]$ : the ratio of females to males was 1:2.1 for the asthma group; 1:1.1 for the wheezy group; and 1:0.9 for the reference group. Smoking habit did not differ significantly between the groups (test for trend $\chi^{2}=3.69$; $\mathrm{p}=0.45)$ : of the asthma group $34(43 \%)$ were current smokers, $13(17 \%)$ were past smokers and $31(40 \%)$ had never smoked; of the wheezy group $38(34 \%)$ were current smokers, $22(20 \%)$ were past smokers and $51(46 \%)$ had never smoked; of the comparison group $33(34 \%)$ were current smokers, $25(26 \%)$ were past smokers and $40(41 \%)$ had never smoked.

Methacholine challenge tests were performed by 204 subjects. Fifteen were excluded from challenge as their baseline FEV1 was less than $70 \%$ predicted (12 in the asthma group and 3 in the wheezy group). Skin tests were carried out on 221 subjects. Blood samples were obtained from 235 subjects: serum IgE levels were obtained for all of these, and RAST results were obtained for 230 .

\section{Symptoms}

A positive response to questions concerning respiratory symptoms in the past 12 months was obtained from 94 subjects: 48 (62\%) of the "asthma" group, 36 (32\%)

Table 1. - Numbers included in the study who carried out allergy tests and methacholine challenge at 35-40 yrs of age

\begin{tabular}{|c|c|c|c|c|c|c|}
\hline \multirow[b]{2}{*}{ Interviews } & \multirow{2}{*}{$\begin{array}{c}\text { Total } \\
\text { n } \\
287\end{array}$} & \multirow{2}{*}{$\begin{array}{c}\begin{array}{c}\text { Asthma } \\
\text { group } \\
(\mathrm{n}=121)\end{array} \\
78 \quad(64)\end{array}$} & \multicolumn{2}{|c|}{$\begin{array}{l}\text { Wheezy } \\
\text { group } \\
(n=167)\end{array}$} & \multicolumn{2}{|c|}{$\begin{array}{c}\text { Comparison } \\
\text { group } \\
(n=167)\end{array}$} \\
\hline & & & 111 & (66) & 98 & (59) \\
\hline Valid skin tests & 221 & 59 (49) & 84 & (50) & 78 & $(47)$ \\
\hline RAST & 230 & $63 \quad(52)$ & 89 & (53) & 78 & (47) \\
\hline Total IgE & 235 & $66(55)$ & 93 & (56) & 76 & (46) \\
\hline $\begin{array}{l}\text { Methacholine } \\
\text { challenge: }\end{array}$ & 219 & $56(46)$ & 87 & (52) & 76 & (46) \\
\hline Carried out test & 204 & 44 (36) & 84 & (50) & 76 & (46) \\
\hline Excluded from test & t 15 & 12 (10) & 3 & (2) & 0 & $(0)$ \\
\hline
\end{tabular}

Values in parentheses are percentage of the original 1964 groups RAST: radio allergosorbent test; IgE: immunoglobulin E. of the wheezy group and $10(10 \%)$ of the comparison group had experienced wheeze in the year prior to the interview (test for trend $\chi^{2}=51.6 ; \mathrm{p}<0.001$ ).

\section{Methacholine challenge tests}

Results of the methacholine challenge tests have been described in detail in a previous report [6]. In brief, for those subjects who were able to perform the challenge test, the asthma group showed significantly greater reactivity to inhaled methacholine than the other two groups which did not differ from each other: of the asthma group, $30(68 \%)$ had a measurable methacholine dose provoking a $20 \%$ fall in FEV1 $\left(\mathrm{PD}_{20}\right)$, compared to 23 $(27 \%)$ of the wheezy group and $16(21 \%)$ of the comparison group (test for trend $\chi^{2}=23.8 ; \mathrm{p}<0.001$ ).

\section{Skin test results}

A greater proportion of subjects in the asthma group $(49 ; 83 \%)$ had at least one positive skin test compared to those with positive tests in the wheezy group (47; $56 \%$ ), who had more with positive skin tests than the comparison group $\left(28 ; 36 \%\right.$ ) (test for trend $\chi^{2}=30.6$; $\mathrm{p}<0.001$ ) (fig. 1). Positive responses to house dust mite were the most common in all three original groups: 49 $(83 \%)$ of the asthma group, $42(50 \%)$ of the wheezy group and $19(24 \%)$ of the comparison group had positive reactions to house dust mite (test for trend $\chi^{2}=45.8$; $\mathrm{p}<0.001)$. Those in the asthma group who responded positively to house dust mite, produced significantly larger wheals than those in the wheezy and comparison groups $(\mathrm{F}=6.44 ; \mathrm{p}=0.002)$ : the mean wheal size of the asthma group was $0.8 \mathrm{~mm}(95 \%$ CI $0.01-1.7)$ greater than the wheezy group and $1.8 \mathrm{~mm}$ (95\% CI 0.7-2.9) greater than the comparison group.

\section{RAST results}

For each of the allergens tested (cat, grass pollen, house dust mite, dog, moulds, trees and weeds), more of the asthma group had positive results than the wheezy or comparison groups. A greater proportion of subjects in the asthma group $(55 ; 87 \%)$ had at least one positive

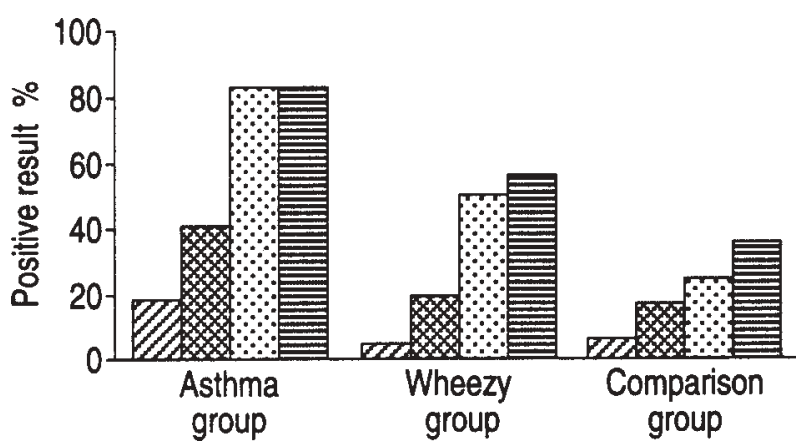

Fig. 1. - Skin test results for the three original groups (at 34-40 yrs of age). $\measuredangle$ : cat; $\$$ : grass pollen; $\because$ : house dust mite; $\equiv$ : at least one positive. 


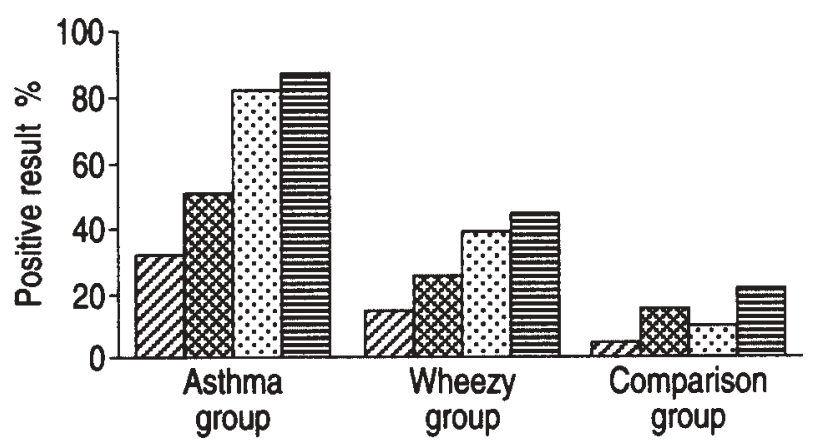

Fig. 2. - Radio allergosorbent test (RAST) results for the three original groups (at 34-40 years of age). $\square$ : cat; house dust mite; $\equiv$ : at least one positive.

RAST result than those in the wheezy group (40; 44\%), who had more with positive results than those in the comparison group $(17 ; 22 \%)$ (test for trend $\chi^{2}=58.4 ; \mathrm{p}<0.001$ ) (fig. 2). As with the skin tests, the most common response was to house dust mite for all groups: $52(83 \%)$ of the asthma group, 35 (39\%) of the wheezy group and 8 (10\%) of the comparison group had positive results for house dust mite (test for trend $\chi^{2}=73.9 ; \mathrm{p}<0.001$ ).

\section{Total serum IgE}

The asthma group had a higher mean $\log \operatorname{IgE}$ value than the wheezy group or the comparison group, which did not differ significantly from each other $(\mathrm{F}=21.72$; p<.0001) (fig. 3).

The relationship of original group, sex, smoking habit and measures of atopy to adult wheezing symptoms

The effects of original group, sex, smoking habit and the three measures of allergic status on wheezing symptoms in the 12 months prior to the interview were investigated using logistic regression analysis. The results for the three measures of atopy were similar, and so an overall atopy measure was calculated: if one of the measures of atopy (skin test result, RAST result or total IgE greater than $120 \mathrm{IU} \cdot \mathrm{mL}^{-1}$ ) was positive, then overall atopy was positive; if all three measures of atopy were negative, then overall atopy was negative. The result of the logistic

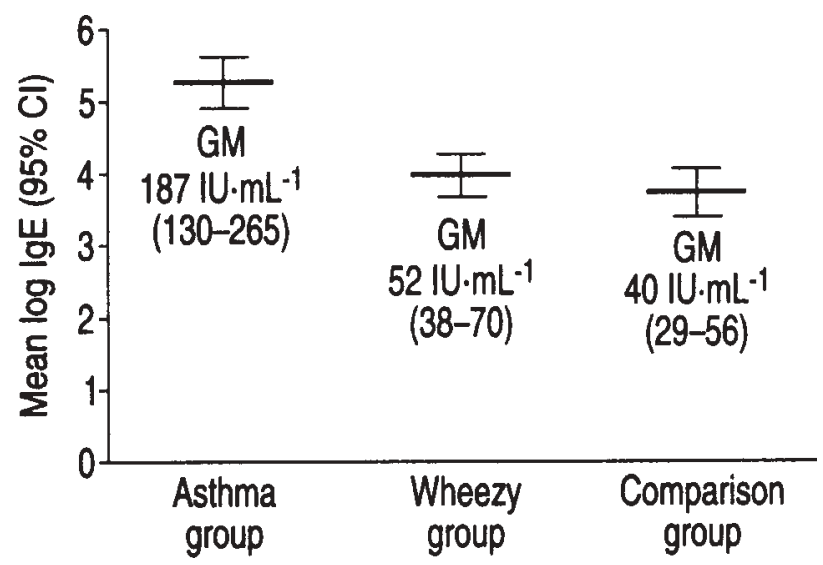

Fig. 3. - Total serum immunoglobulin E (IgE) results of the three original groups (at 34-40 yrs of age). Geometric mean (GM) with 95\% CI are shown. 95\% CI: $95 \%$ confidence interval.
Table 2. - The effect of original group, gender, smoking habit and overall atopic status at 34-40 yrs of age on adult wheezing symptoms $(\mathrm{n}=287)$

\begin{tabular}{lcccc}
\hline & $\begin{array}{c}\text { Wheeze in } \\
\text { past } 12 \\
\text { months }\end{array}$ & No wheeze & $\begin{array}{c}\text { Odds ratio } \\
(95 \% \mathrm{CI}) \dagger\end{array}$ \\
\hline $\begin{array}{l}\text { Original group } \\
\text { Asthma }\end{array}$ & 48 & 30 & 11.86 & $(4.97-28.33) \#$ \\
Wheezy & 36 & 75 & 4.02 & $(1.82-8.90) \#$ \\
$\begin{array}{l}\text { Comparison } \\
\text { Sex }\end{array}$ & 10 & 88 & 1 & \\
$\begin{array}{l}\text { Male } \\
\text { Female }\end{array}$ & 50 & 108 & 0.57 & $(0.32-1.04)$ \\
Smoking habit & 44 & 85 & 1 & \\
$\begin{array}{l}\text { Current } \\
\text { Past }\end{array}$ & 43 & 62 & 1.89 & $(1.00-3.56) \#$ \\
Never & 16 & 44 & 1.24 & $(0.57-2.71)$ \\
Overall atopy & 35 & 87 & 1 & \\
Positive & 71 & 84 & 2.53 & $(1.15-5.56) \#$ \\
Missing & 12 & 45 & 0.90 & $(0.34-2.43)$ \\
Negative & 11 & 64 & 1 & \\
\hline
\end{tabular}

$\dagger$ : estimates of odds ratios were obtained from the logistic regression analysis; \#: as the confindence interval does not include 1, this group of subjects is significantly different from the reference caregory at the 5\% significance level. 95\% CI: 95\% confidence interval.

regression including overall atopy (table 2) showed that the asthma group was 12 times more likely to have adult wheezing symptoms than the comparison group, and that the wheezy group was four times more likely to have adult symptoms than the comparison group. Males were not more likely to have adult wheeze than females. Current smokers were marginally more likely to have wheezing symptoms than subjects who had never smoked, but past smokers did not differ from nonsmokers. Subjects with at least one positive measure of atopy were 2.5 times more likely to wheeze than those with all negative atopy tests. A logistic regression was also carried out including an interaction of original group with atopy, to investigate if children with asthma or wheeze who were atopic as adults were more likely to have symptoms than those who were not atopic. None of the interaction terms proved to be significant.

The relationship of original group, sex, smoking habit and measures of atopy to methacholine challenge test result

The effects of original group, sex, smoking habit and the overall atopy measure on methacholine challenge test result was investigated using logistic regression analysis (table 3). The logistic regression demonstrated that the asthma group was seven times more likely to have a positive methacholine challenge test than the comparison group, but wheeze in childhood was not associated with a positive methacholine challenge test. Males were less likely to have a positive methacholine challenge test than females. Smoking habit did not have any additive effect. Subjects with at least one positive measure of 
Table 3. - The effect of original group, gender, smok ing habit and overall atopic status at 34-40 yrs of age on methacholine (Mch) challenge result $(n=204)$

\begin{tabular}{lccl}
\hline & $\begin{array}{c}\text { Cases with } \\
\text { +ve Mch }\end{array}$ & $\begin{array}{c}\text { Cases with } \\
\text {-ve Mch }\end{array}$ & $\begin{array}{c}\text { Odds ratio } \\
(95 \% \text { CI })\end{array}$ \\
\hline $\begin{array}{l}\text { Original group } \\
\text { Asthma }\end{array}$ & 30 & 14 & $7.58(2.84-20.27) \#$ \\
$\begin{array}{l}\text { Wheezy } \\
\text { Comparison }\end{array}$ & 23 & 59 & $1.34(0.61-2.99)$ \\
Sex & 16 & 62 & 1 \\
Male & 29 & 85 & $0.33(0.16-0.69) \#$ \\
Female & 40 & 50 & 1 \\
Smoking habit & & & \\
Current & 27 & 44 & $0.97(0.46-2.05)$ \\
Past & 9 & 33 & $0.49(0.19-1.28)$ \\
Never & 33 & 58 & 1 \\
Overall atopy & & & \\
Positive & 69 & 57 & $2.65(1.18-5.98) \#$ \\
Missing & 5 & 1 & $1.20(0.12-12.25)$ \\
Negative & 61 & 11 & 1 \\
\hline
\end{tabular}

$t$ : estimates of odds ratios were obtained from the logistic regression analysis; \#: as the confidence interval does not include 1, this group of subjects is significantly different from the reference category at the 5\% significance level. 95\% CI: $95 \%$ confidence interval.

atopy were 2.6 times more likely to have a positive methacholine challenge test than those with all negative atopy tests. A logistic regression was also carried out including an interaction of original group with atopy, to investigate if children with asthma or wheeze who are atopic were more likely to have a positive challenge test than those who were not atopic. None of the interaction terms proved to be significant. The results were similar for each of the three individual measures of atopy.

\section{Discussion}

In this study, original childhood grouping (asthma, wheeze only with infection, or no symptoms) and atopy (defined by skin testing, or RAST test, or total IgE greater than $120 \mathrm{IU} \cdot \mathrm{mL}^{-1}$ ) were found to independently predict the likelihood of wheezing symptoms and of bronchial hyperresponsiveness in middle age. No significant interactions between these factors were observed. Current smoking was associated with wheezing symptoms but not with bronchial hyperresponsiveness. Gender had no effect on likelihood of symptoms, but was associated with bronchial hyperresponsiveness, females being more likely to have a positive methacholine challenge result than males.

Associations between atopic status and wheezing symptoms have been investigated by other authors [11-15]. GERRITSEN et al. [11] found that the adult symptoms were not predicted by skin test reactivity in a group of childhood asthmatics. However, $95 \%$ of the subjects had positive skin test reactivity to house dust mite in childhood and $98 \%$ in adulthood, therefore skin testing was unlikely to be predictive of adult respiratory symptoms. Our results are in contrast to those of GERRITSEN et al.
[11] and amplify those reported in a smaller group (51 subjects) studied by DE GOOUER et al. [12] at age 8-11 yrs and at age 35-38 yrs. They found childhood atopy to be a risk factor for respiratory symptoms in adulthood. Interestingly, smoking was not related to symptoms, although they did not distinguish between current and past smoking. JENKINS et al. [13] reported that independent predictors for asthma symptoms at 29-32 yrs of age included a history of asthma in childhood and a selfreported personal or parental history of atopy in childhood together with reduced lung function in childhood. The Melbourne group, following up asthmatic children and controls identified at $7 \mathrm{yrs}$ of age, and an additional group of more severe asthmatics identified at $10 \mathrm{yrs}$ of age, also found an association between atopy and symptoms. At $21 \mathrm{yrs}$, their asthma group had significantly more hay fever or eczema and more positive skin tests compared to control subjects [14]. As the severity of wheezing increased, there was an increase in reported atopic illnesses and number and size of positive skin test reactions. When the subjects were studied at $28 \mathrm{yrs}$ of age, similar results were apparent, with skin test reactions being strongest and serum IgE levels being highest in the subjects with most severe wheezing symptoms [15]. In these reports, they did not distinguish between children who had asthma and those who had wheezy bronchitis in childhood. However, in more recent reports describing the same subjects at $35 \mathrm{yrs}$ of age [16, 17], they have adopted this classification and have reported findings similar to ours [6], i.e. that subjects who had wheezy bronchitis are less likely to have wheeze [16] and more likely to have normal pulmonary function at age 35 yrs than those who had asthma as children [17]. They have not yet reported their findings in relation to atopy and it will be interesting if, using this classification, they find similar independent effects of grouping and atopic status.

In our study, atopy, in addition to predicting symptoms, also predicts bronchial responsiveness to methacholine. After taking into account the effects of childhood asthma and gender on bronchial reactivity, positive atopy test results were still associated with positive bronchial challenge test results: although overall atopy testing is reported (table 3), analyses using each individual measure (skin test results, RAST or IgE measurement) gave similar results.

Earlier studies had suggested that atopic status and bronchial reactivity were not associated. WoOLCOCK et al. [18] found no correlation between methacholine reactivity and skin test response in a nonasthmatic population, and ANNESI et al. [19] also failed to demonstrate an association between IgE level and bronchial reactivity in Parisian policemen. BRYANT and BURNS [20] stated that there was not a significant association between degree of bronchial histamine reactivity and either total serum $\mathrm{IgE}$ level or skin test reactivity. However, they studied small groups of subjects with asthma, rhinitis, or no symptoms, and had methodological problems in matching groups for age. The Melbourne group also concluded that bronchial hyperreactivity and atopy were not directly linked [14], but closer examination of their 
results reveals an overall association between a variety of skin tests and the degree of bronchial reactivity, and also between total IgE and reactivity. When they restricted analysis to subjects with current wheezing, group sizes were small and the association was weakened, although a significant effect of $\operatorname{IgE}$ on reactivity was still detected by nonparametric testing.

A possible association of atopy with airway hyperresponsiveness was also found by DE GoOIJER et al. [12] who reported that airway hyperresponsiveness was more common in adults who were atopic in childhood, but the authors were unable to use logistic regression analysis to examine factors for airway hyperresponsiveness due to small numbers.

Larger random community studies have shown that bronchial reactivity is associated with atopy, expressed in some studies as raised IgE levels [21-24], and in others as positive skin test reactivity $[23,25,26]$. This association has been demonstrated in children, adolescents and adults. For example, BuRRows et al. [22] found that bronchial responsiveness to methacholine was related to high serum $\operatorname{IgE}$ in a study of 11 year old New Zealand children. In adolescents and children, BACKER et al. [23] showed that the degree of bronchial responsiveness to histamine was significantly correlated with the degree of atopy (expressed as the sum of all the allergen wheal areas). WITT et al. [24] studied allergy and bronchial reactivity to histamine in children and adults: they noted that the prevalence of bronchial responsiveness was greater in skin prick test responders, and that those with bronchial reactivity had higher total serum IgE levels. COCKCROFT et al. [25] and BURNEY et al. [26] demonstrated a significant relationship between skin test reaction and increased bronchial responsiveness to histamine. In a study of middle-aged and elderly men, O'CONNOR et al. [21] suggested that smoking and atopy may act synergistically to increase the degree of nonspecific airway hyperresponsiveness. In subjects selected from a student population, CoOKSON et al. [27] found a strong positive association between the presence of positive skin tests and a high level of bronchial responsiveness to methacholine. Recently, studying a large random population sample of 2,415 adults aged 18-70 yrs, BRITTON et al. [28] have confirmed the independent effect of atopy as a determinant of bronchial reactivity in the general population.

Reports differ on the effects of gender on outcome. In our study, as in that of DE GoOIJER et al. [12], we found no influence of gender on symptoms, although females in our study were more likely to have bronchial responsiveness; we previously suggested that this difference was due to lower starting FEV1 values in females [6]. Jenkins et al. [13] reported that being female was an independent predictor of asthma symptoms in adulthood, and in a follow-up study of subjects who had childhood asthma, females had a greater likelihood of persistent symptoms in adulthood [29].

Our study must be interpreted with caution for three reasons. The first is that response rates for allergy and challenge testing range from $46 \%$ to $56 \%$ of original subjects from the 1964 study, raising the possibility of selection bias. However, these response rates represent $71-85 \%$ of subjects interviewed, and analyses of symptoms reported by subjects who attended for interview $(n=287)$ did not differ from those of a further 73 who were contacted by post. The gender distribution of subjects in the three groups also reflected the 1964 pattern. We are, therefore, reasonably confident that our present results are representative of the whole group. The second reason for caution is that measurements of atopic status were not made in 1964 when the children were originally classified. However, even allowing for some loss of atopic phenotype as subjects grow older [25, $30]$, the association of atopy with childhood wheeze in the presence of infection appears to be weaker than that with asthma. The third reason is that although the original childhood definition of asthma as "recurrent dyspnoea of an obstructive type without demonstrable cause" was clear, the classification of children having "wheeze in the presence of upper respiratory infection" was less distinct. Three alternative descriptions are possible for the composition of the wheezy group: it could be a homogeneous group of children with a different disease entity from asthma; it could consist of two types of children, some with asthma, others who resemble asymptomatic children; or, it could be a group of children with asthma of a lesser degree of severity than those classified as having asthma. Our previous work, as well as the results presented here, tend to support the first hypothesis, that the wheezy subjects belong to a group with a different disease entity, since the outcome for children in this group is clearly different from those in the childhood asthma group.

In summary, atopy is an important predictor of persistent problems in adult life, but it alone does not account for the difference in adult outcome between the group who wheezed only with infection and the group who had asthma in childhood. The mechanisms of childhood wheeze cannot be defined in our study, but the observations that lung function and bronchial reactivity becomes normal in middle age for many subjects suggests that other factors, for example lung mechanics and airway geometry, may be responsible for their childhood problems.

Acknowledgements: The authors are grateful to J. Leys for technical assistance and to J. Lemon for computing advice.

\section{References}

1. Speight ANP. Is childhood asthma being underdiagnosed and undertreated? Br Med J 1978; 2: 331-332.

2. Speight ANP, Lee DA, Hey EN. Underdiagnosis and undertreatment of asthma in childhood. Br Med J 1983; 286: $1253-1256$

3. Martinez FD, Wright AL, Taussig LM, Holberg CJ, Halonen M, Morgan WJ. Asthma and wheezing in the first six years of life. N Engl J Med 1995; 332: 133-138.

4. Dawson B, Horobin G, Illsley R, Mitchell R. A survey of childhood asthma in Aberdeen. Lancet 1969; i: 827830 . 
5. Mitchell RG, Dawson B. Educational and social characteristics of children with asthma. Arch Dis Child 1973; 48: 467-471.

6. Godden DJ, Ross S, McMurray D, et al. Outcome of wheeze in childhood: symptoms and pulmonary function 25 years later. Am J Respir Crit Care Med 1994; 149: 106-112.

7. Ross S, Godden D, McMurray D, et al. Social effects of wheeze in childhood: a 25 year follow-up. $\mathrm{Br}$ Med J 1992; 305: 545-548.

8. Yan K, Salome C, Woolcock AJ. Rapid method for management of bronchial responsiveness. Thorax 1983; 38: 760-765.

9. Chanal I, Horst M, Segalen C, Dreborg S, Michel FB, Bousquet I. Comparison between modified skin prick tests with standardised allergen extracts and Phazet. $J$ Allergy Clin Immunol 1988; 82: 871-881.

10. Kjellman NIM, Dreborg S, Falth-Magnusson K. Allergy screening including a comparison of prick test results with allergen-coated lancets (Phazet) and liquid extracts. Allergy 1988; 43: 277-283.

11. Gerritsen J, Koeter GH, de Monchy JGR, Knol K. Allergy in subjects with asthma from childhood to adulthood. $J$ Allergy Clin Immunol 1990; 85: 116-125.

12. de Gooijer A, Brand PLP, Gerritsen J, Koeter GH, Postma DS, Knol K. Changes in respiratory symptoms and airway hyperresponsiveness after 27 years in a populationbased sample of schoolchildren. Eur Respir J 1993; 6: 848-854.

13. Jenkins MA, Hopper JL, Bowes G, Carlin JB, Flander LB, Giles GG. Factors in childhood as predictors of asthma in adult life. Br Med J 1994; 309: 90-93.

14. Martin AJ, Landau LI, Phelan PD. Natural history of allergy in asthmatic children followed to adult life. Med J Aust 1981; 2: 470-474.

15. Kelly WJW, Hudson I, Phelan PD, Pain MCF, Olinsky A. Atopy in subjects with asthma followed to the age of 28 yrs. J Allergy Clin Immunol 1990; 85: 548-557.

16. Oswald H, Phelan PD, Lanigan A, Hibbert M, Bowes G, Olinsky A. Outcome of childhood asthma in midadult life. Br Med J 1994; 309: 95-96.

17. Oswald H, Phelan PD, Lanigan A, et al. Childhood asthma and lung function in mid adult life. Am J Respir Crit Care Med 1994; 149: A912.

18. Woolcock AJ, Colman MH, Jones MW. Atopy and bronchial reactivity in Australian and Melanesian populations. Clin Allergy 1978; 8: 155-164.
19. Annesi I, Orycszczyn M-P, Frette C, Neukirch F, OrvoenFrija E, Kauffmann F. Total circulating IgE and FEV1 in adult men: an epidemiologic longitudinal study. Chest 1992; 101: 642-648.

20. Bryant DH, Bums MW. The relationship between bronchial histamine reactivity and atopic status. Clin Allergy 1976; 6: 373-381.

21. O'Connor GT, Sparrow D, Segal HR, Weiss ST, Eleuteri D. Smoking, atopy, and methacholine airway responsiveness among middle-aged and elderly men. Am Rev Respir Dis 1989; 140: 1520-1527.

22. Burrows B, Sears MR, Flannery EM, Herbison GP, Holdaway MD. Relationships of bronchial responsiveness assessed by methacholine to serum IgE, lung function, symptoms, and diagnoses in 11 year old New Zealand children. J Allergy Clin Immunol 1992; 90: 376-385.

23. Backer V, Ulrik CS, Hansen KK, Laursen EM, Dirksen A, Bach-Mortensen N. Atopy and bronchial responsiveness in a random population sample of 527 children and adolescents. Ann Allergy 1992; 96: 116-122.

24. Witt C, Stuckey MS, Woolcock AJ, Dawkins RL. Positive allergy prick tests associated with bronchial histamine responsiveness in an unselected population. J Allergy Clin Immunol 1986; 77: 698-702.

25. Cockcroft DW, Murdock KY, Berscheid BA. Relationship between atopy and bronchial responsiveness to histamine in a random population. Ann Allergy 1984; 53: 26-29.

26. Burney PGJ, Britton JR, Chinn S, et al. Descriptive epidemiology of bronchial reactivity in an adult population: results from a community study. Thorax 1987; 42: 38-40.

27. Cookson WOCM, Musk AW, Ryan G. Associations between asthma history, atopy, and nonspecific bronchial responsiveness in young adults. Clin Allergy 1986; 16: 425-432.

28. Britton J, Pavord I, Richards K, Knox A, et al. Factors affecting the occurrence of airway hyperreactivity in the general population: the importance of atopy and airway calibre. Eur Respir J 1994; 7: 881-887.

29. Roorda RJ, Gerritsen J, van Aalderen WMC, et al. Followup of asthma from childhood to adulthood: influence of potential risk factors on the outcome of pulmonary function and bronchial responsiveness in adulthood. $J$ Allergy Clin Immunol 1994; 93: 575-584.

30. Cline MG, Burrows B. Distribution of allergy in a population sample residing in Tucson, Arizona. Thorax 1989; 44: 425-431. 